\title{
The influence of postoperative albumin levels on the outcome of cardiac surgery
}

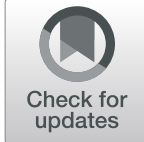

David Berbel-Franco ${ }^{1}$, Juan Carlos Lopez-Delgado ${ }^{1,2^{*}} \mathbb{D}$, Alessandro Putzu ${ }^{3}$, Francisco Esteve ${ }^{1,2}$, Herminia Torrado ${ }^{1}$, Elisabet Farrero ${ }^{1}$, David Rodríguez-Castro ${ }^{1}$, Maria Lluïsa Carrio ${ }^{1}$ and Giovanni Landoni ${ }^{4,5}$

\begin{abstract}
Background: The prognostic role of low postoperative serum albumin levels (SAL) after cardiac surgery (CS) remains unclear in patients with normal preoperative SAL. Our aim was to evaluate the influence of SAL on the outcome of CS.
\end{abstract}

Methods: Prospective observational study. Patients undergoing CS with normal preoperative SAL and nutritional status were included and classified into different subgroups based on SAL at $24 \mathrm{~h}$ after CS. We assessed outcomes (i.e., in-hospital mortality, postoperative complications and long-term survival) and results were analyzed among the different subgroups of SAL.

Results: We included 2818 patients. Mean age was $64.5 \pm 11.6$ years and body mass index $28.0 \pm 4.3 \mathrm{Kg} \cdot \mathrm{m}^{-2}$. $5.8 \%(n=162)$ of the patients had normal SAL levels $\left(\geq 35 \mathrm{~g} \cdot \mathrm{L}^{-1}\right), 32.8 \%(n=924)$ low deficit $\left(30-34.9 \mathrm{~g} \cdot \mathrm{L}^{-1}\right)$, $44.3 \%(n=1249)$ moderate deficit $\left(25-29.9 \mathrm{~g} \cdot \mathrm{L}^{-1}\right)$, and $17.1 \%(n=483)$ severe deficit $\left(<25 \mathrm{~g} \cdot \mathrm{L}^{-1}\right)$. Higher SAL after CS was associated with reduced in-hospital (OR:0.84;95\% Cl:0.80-0.84; $P=0.007$ ) and long-term mortality (HR: $0.85 ; 95 \%$ Cl:0.82-0.87;P<0.001). Subgroups of patients with lower SAL showed worst long-term survival (5-year mortality:94.3\% normal subgroup, $87.4 \%$ low, $83.1 \%$ moderate and $72.4 \%$ severe; $P<0.001$ ). Multivariable analysis showed higher in-hospital mortality, sepsis, hemorrhage related complications, and ICU stay in subgroups of patients with lower SAL. Predictors of moderate and severe hypoalbuminemia were preoperative chronic kidney disease, previous CS, and longer cardiopulmonary bypass time.

Conclusions: The presence of postoperative hypoalbuminemia after CS is frequent and the degree of hypoalbuminemia may be associated with worst outcomes, even in the long-term scenario.

Keywords: Cardiac surgery, Serum albumin levels, Perioperative medicine, Postoperative outcomes, In-hospital, Long-term mortality

\footnotetext{
* Correspondence: juancarloslopezde@hotmail.com

${ }^{1}$ Intensive Care Department, Hospital Universitari de Bellvitge, C/Feixa Llarga s/n. 08907, L'Hospitalet de Llobregat, Barcelona, Spain

${ }^{2}$ IDIBELL (Institut d'Investigació Biomèdica Bellvitge; Biomedical Investigation Institute of Bellvitge), Avda. Gran Via de L'Hospitalet 199, 08908, L'Hospitalet de Llobregat, Barcelona, Spain

Full list of author information is available at the end of the article
}

(C) The Author(s). 2020 Open Access This article is licensed under a Creative Commons Attribution 4.0 International License, which permits use, sharing, adaptation, distribution and reproduction in any medium or format, as long as you give appropriate credit to the original author(s) and the source, provide a link to the Creative Commons licence, and indicate if changes were made. The images or other third party material in this article are included in the article's Creative Commons licence, unless indicated otherwise in a credit line to the material. If material is not included in the article's Creative Commons licence and your intended use is not permitted by statutory regulation or exceeds the permitted use, you will need to obtain permission directly from the copyright holder. To view a copy of this licence, visit http://creativecommons.org/licenses/by/4.0/. The Creative Commons Public Domain Dedication waiver (http://creativecommons.org/publicdomain/zero/1.0/) applies to the data made available in this article, unless otherwise stated in a credit line to the data. 


\section{Background}

Liver proteins, such as albumin, have been considered over time as indicators of morbidity and mortality, as well as recovery markers of acute and chronic disease [1]. Serum levels may identify patients most likely to develop malnutrition or with a previous poor nutritional status, even when adequate nutritional supplementations during hospital stay is being performed [1]. Indeed, recent published guidelines suggest that surgery should be avoided in patients with low preoperative serum albumin levels (SAL) $\left(<30 \mathrm{~g} \cdot \mathrm{L}^{-1}\right)$ due to its association with worst outcomes and impaired nutritional status [2].

Low preoperative SAL are associated with complications and mortality in the setting of cardiac surgery (CS) in patients who underwent coronary artery bypass graft (CABG), as well as other anthropometric values associated with nutritional status, such as body mass index (BMI) [3]. However, no correlation between low BMI $\left(<20 \mathrm{~kg} \cdot \mathrm{m}^{-2}\right)$ and low SAL $\left(<25 \mathrm{~g} \cdot \mathrm{L}^{-1}\right)$ has been reported [4]. Furthermore, SAL has been considered as an independent prognosis marker in several studies related with CS procedures, even in the setting of newer technology, such as transcatheter aortic valve replacement and left-ventricular assist device [5-7]. The level of hypoalbuminemia required to increase the risk of these outcomes has not been properly defined and varies depending on the study (i.e., under 20,35 or $\left.40 \mathrm{~g} \cdot \mathrm{L}^{-1}\right)$ [8-10]. Increased risk of postoperative infection in patients with low preoperative SAL has also been reported [11].

The presence of low postoperative SAL after CS may be caused by several factors apart from low preoperative SAL, which include surgical injury, dilution due to fluid resuscitation, blood loss and cardiopulmonary bypass (CPB) among other factors [12]. The associated underlying pathophysiological mechanism is mainly related with the degree of ischemiareperfusion injury or systemic inflammatory response syndrome (SIRS) produced during CS and a higher degree of SIRS is associated with higher risk of morbidities and mortality [13]. However, excessive fluid reanimation and blood loss can also influence in the occurrence of lower postoperative SAL [12]. Thus, postoperative hypoalbuminemia is the summation of different factors associated with outcomes after CS and postoperative SAL may have prognosis implications.

It is well known that the early identification of patients at risk for poor outcome after CS may be helpful in modifying patient care strategy in the Intensive Care Unit (ICU) in order to improve outcomes. A better understanding of the different aspects that contribute to morbidity and mortality is needed because CS population trend towards aging and an increasing incidence of comorbidities which ultimately affects the frailty of these patients [14]. In addition, measuring long-term outcomes is a marker of the quality of perioperative care in CS [15]. Monitoring of postoperative SAL may be a helpful tool for risk stratification and prognosis assessment due to the different cumulative aspects that SAL entails (e.g., inflammatory response, fluid status and malnutrition) [12]. The aim of the present study was to evaluate the influence of postoperative SAL on the short- and long-term outcomes of patients who underwent CS with normal preoperative SAL. We also aimed to identify those factors related with postoperative moderate to severe hypoalbuminemia $\left(<30 \mathrm{~g} \cdot \mathrm{L}^{-1}\right)$.

\section{Methods}

A prospective observational study was performed in a surgical Intensive Care Unit (ICU) of a university affiliated referral hospital between June 2006 and September 2011. All consecutive patients undergoing different types of CS with preoperative normal albumin levels (i.e., SAL $>35 \mathrm{~g} \cdot \mathrm{L}^{-1}$ ) and appropriate nutritional status (evaluated by means of Subjective Global Assessment) were considered for the study. Hearttransplant patients were excluded due to the potential influence of immunosuppressant and/or corticosteroid therapy over postoperative SAL and inflammatory response (see Supplementary Figure 1). The study was approved by the Institutional Ethics Committee of our hospital (Comité d'Ėtica i Assajos Clínics de Hospital Universitari de Bellvitge; Barcelona, Spain); with approval number 39/07. Informed consent was waived due to the observational nature of our study (Details of the ethics approval and study protocol are provided as supplementary material).

Data were prospectively extracted from the medical registry of each patient and collected in a local database for analysis purposes. Preoperative data (demographic data, comorbidities and treatment before surgery), operative data and postoperative variables were routinely collected together with CS scores (Parsonnet, European System for Cardiac Operative Risk Evaluation (EuroSCORE)) and ICU scores (Acute Physiology and Chronic Health Evaluation (APACHE) II and III, Simplified Acute Physiology Score (SAPS) II and III). A follow-up during $4.6 \pm 2.4$ years was performed in 2565 patients (Follow-up was not possible in 94 patients that were alive at hospital discharge). The long-term follow-up was performed using the Catalan Health Central Registry (Registre Central de Persones Assegurades). 
Table 1 Preoperative (A), intraoperative and postoperative (B) characteristics of the population

\begin{tabular}{|c|c|c|c|c|}
\hline A & All patients $(n=2818)$ & $\begin{array}{l}\text { Hospital Survivors } \\
(n=2659 ; 94.4 \%)\end{array}$ & $\begin{array}{l}\text { Non-survivors } \\
(n=159 ; 5.6 \%)\end{array}$ & $P$ \\
\hline \multicolumn{5}{|l|}{ Preoperative data } \\
\hline Age (years) & $64.5 \pm 11.6$ & $64.2 \pm 11.6$ & $69.7 \pm 10$ & $<0.001$ \\
\hline Sex (male) & $63.8 \%(1799)$ & $63.7 \%(1696)$ & $64.7 \%(103)$ & 0.86 \\
\hline $\mathrm{BMI}\left(\mathrm{Kg} \cdot \mathrm{m}^{-2}\right)$ & $28.0 \pm 4.3$ & $27.9 \pm 4.3$ & $28.0 \pm 4.6$ & 0.89 \\
\hline Albumin before surgery $\left(\mathrm{g} \cdot \mathrm{L}^{-1}\right)$ & $40.0 \pm 3.5$ & $40.1 \pm 2.8$ & $39.9 \pm 1.5$ & 0.85 \\
\hline Subjective Global Assessment (class B) & $5.8 \%(163)$ & $5.9 \%(158)$ & $3.1 \%(5)$ & 0.25 \\
\hline Hypertension & $62.7 \%(1768)$ & $62.1 \%(1650)$ & $74.2 \%(118)$ & 0.002 \\
\hline Diabetes Mellitus & $24.8 \%(699)$ & $24.9 \%(662)$ & $33.3 \%(53)$ & 0.03 \\
\hline Dyslipidemia & $50.5 \%(1423)$ & $50.4 \%(1339)$ & $52.8 \%(84)$ & 0.56 \\
\hline Peripheral vascular disease & $8.8 \%(249)$ & $8.3 \%(220)$ & $18.2 \%(29)$ & $<0.001$ \\
\hline Chronic renal insufficiency & $5.2 \%(146)$ & $4.6 \%(122)$ & $15.1 \%(24)$ & $<0.001$ \\
\hline Renal failure (on Dialysis) & $0.8 \%(23)$ & $0.8 \%(20)$ & $1.9 \%(3)$ & 0.14 \\
\hline Creatinine before surgery $\left(\mu \mathrm{mol} \cdot \mathrm{I}^{-1}\right)$ & $96 \pm 59$ & $94 \pm 58$ & $119 \pm 67$ & $<0.001$ \\
\hline Previous stroke & $5.6 \%(158)$ & $5.5 \%(145)$ & $8.2 \%(13)$ & 0.15 \\
\hline COPD & $12 \%(337)$ & $11.5 \%(307)$ & $18.9 \%(30)$ & 0.008 \\
\hline Active smokers & $15.5 \%(437)$ & $15.3 \%(407)$ & $18.8 \%(30)$ & 0.58 \\
\hline Previous atrial fibrillation & $23.8 \%(671)$ & $23.3 \%(620)$ & $32.8 \%(51)$ & 0.005 \\
\hline Previous myocardial infarction & $15.5 \%(437)$ & $15.3 \%(407)$ & $18.9 \%(30)$ & 0.26 \\
\hline Recent myocardial infarction & $11 \%(310)$ & $10.5 \%(278)$ & $20.1 \%(32)$ & 0.001 \\
\hline On B-Blockers & $41.3 \%(1165)$ & $41.4 \%(1102)$ & $39.6 \%(63)$ & 0.68 \\
\hline On statins & $41.2 \%(1160)$ & $41.3 \%(1097)$ & $39.6 \%(63)$ & 0.74 \\
\hline On Aspirin & $44.5 \%(1184)$ & $44.5 \%(1184)$ & $43.4 \%(69)$ & 0.81 \\
\hline On diuretics & $47.6 \%(1340)$ & $46.6 \%(1239)$ & $63.5 \%(101)$ & 0.001 \\
\hline Hypertrophic cardiomyopathy & $31.2 \%(880)$ & $31 \%(826)$ & $33.9 \%(54)$ & 0.59 \\
\hline Dilated cardiomyopathy & $20.4 \%(577)$ & $20.2 \%(537)$ & $25.1 \%(40)$ & 0.19 \\
\hline LVEF (\%) & $60 \pm 12$ & $59 \pm 13$ & $60 \pm 12$ & 0.25 \\
\hline PAP (mmHg) & $46 \pm 16$ & $45 \pm 15$ & $49 \pm 16$ & 0.04 \\
\hline Hemoglobin before surgery $\left(\mathrm{g} \cdot \mathrm{dL}^{-1}\right)$ & $13.0 \pm 1.7$ & $13.0 \pm 1.7$ & $12.0 \pm 1.9$ & 0.001 \\
\hline Platelet count before surgery $\left(1 \cdot \mathrm{nl}^{-\mathbf{1}}\right)$ & $215 \pm 68$ & $216 \pm 68$ & $208 \pm 75$ & 0.24 \\
\hline Emergent surgery & $5.1 \%(143)$ & $4.5 \%(120)$ & $14.5 \%(23)$ & $<0.001$ \\
\hline Past cardiac surgery & $9.4 \%(266)$ & $9.2 \%(245)$ & $13.2 \%(21)$ & 0.09 \\
\hline EuroSCORE & $5.9 \pm 3$ & $5.7 \pm 2.8$ & $8.6 \pm 3.8$ & $<0.001$ \\
\hline Parsonnet score & $11.4 \pm 7.4$ & $11.2 \pm 7.2$ & $15.4 \pm 9.8$ & $<0.001$ \\
\hline B & All patients $(n=2818)$ & $\begin{array}{l}\text { Hospital } \\
\text { Survivors } \\
(n=2659 ; 94.4 \%)\end{array}$ & $\begin{array}{l}\text { Non-survivors } \\
(\mathrm{n}=159 ; 5.6 \%)\end{array}$ & $P$ \\
\hline \multicolumn{5}{|l|}{ Intraoperative data } \\
\hline Isolated CABG & $32.2 \%(907)$ & $32.3 \%(859)$ & $30.2 \%(48)$ & 0.86 \\
\hline Isolated valve surgery & $51.7 \%(1456)$ & $52 \%(1382)$ & $46.5 \%(74)$ & 0.65 \\
\hline$C A B G+$ valve surgery & $6.9 \%(194)$ & $6.7 \%(178)$ & $10.1 \%(16)$ & 0.09 \\
\hline Other cardiac surgery & $9.2 \%(261)$ & $9 \%(240)$ & $13.2 \%(21)$ & 0.06 \\
\hline Number of bypass & $3(2-4)$ & $3(2-4)$ & $3(2-4)$ & 0.85 \\
\hline CPB time (min) & $112 \pm 41$ & $111 \pm 39$ & $140 \pm 62$ & 0.001 \\
\hline ACC time (min) & $74 \pm 30$ & $73 \pm 29$ & $84 \pm 37$ & 0.001 \\
\hline
\end{tabular}


Table 1 Preoperative (A), intraoperative and postoperative (B) characteristics of the population (Continued)

\begin{tabular}{|c|c|c|c|c|}
\hline \multicolumn{5}{|l|}{ Postoperative data } \\
\hline APACHE ॥ & $12.3 \pm 4.6$ & $11.8 \pm 4.1$ & $19 \pm 6.8$ & $<0.001$ \\
\hline APACHE III & $50 \pm 18.3$ & $48.2 \pm 16$ & $78.1 \pm 27.8$ & $<0.001$ \\
\hline SAPS $\|$ & $24 \pm 9.6$ & $23.3 \pm 8.4$ & $38 \pm 14.6$ & $<0.001$ \\
\hline SAPS III & $40.0 \pm 10.4$ & $39.3 \pm 9.6$ & $51.8 \pm 13.5$ & $<0.001$ \\
\hline Ventilation time (hours) & $51 \pm 129$ & $39 \pm 99$ & $248 \pm 309$ & $<0.001$ \\
\hline $\mathrm{PaO} 2 / \mathrm{FiO} 2$ ratio on admission & $331 \pm 98$ & $333 \pm 97$ & $290 \pm 112$ & $<0.001$ \\
\hline $\mathrm{PaO} 2 / \mathrm{FiO} 2$ ratio $12 \mathrm{~h}$ after admission & $311 \pm 89$ & $315 \pm 87$ & $249 \pm 98$ & $<0.001$ \\
\hline $\mathrm{PaO} 2 / \mathrm{FiO} 2$ ratio $24 \mathrm{~h}$ after admission & $308 \pm 76$ & $312 \pm 73$ & $236 \pm 92$ & $<0.001$ \\
\hline Reintubation & $1.1 \%(31)$ & $1 \%(25)$ & $3.8 \%(6)$ & 0.01 \\
\hline Tracheostomy & $1.3 \%(35)$ & $1 \%(26)$ & $5.7 \%(9)$ & 0.005 \\
\hline Need of vasoactive drugs (hours) & $103 \pm 141$ & $91 \pm 116$ & $253 \pm 271$ & $<0.001$ \\
\hline LCOS & $41.5 \%(1170)$ & $38.8 \%(1034)$ & $85.5 \%(136)$ & $<0.001$ \\
\hline PMl & $11.6 \%(327)$ & $10.2 \%(272)$ & $34.6 \%(55)$ & $<0.001$ \\
\hline IABP support & $7.8 \%(222)$ & $6.7 \%(180)$ & $26.4 \%(42)$ & $<0.001$ \\
\hline Atrial Fibrilation & $39.5 \%(1114)$ & $37.9 \%(1009)$ & $66 \%(105)$ & $<0.001$ \\
\hline Albumin $24 \mathrm{~h}$ after surgery $\left(\mathrm{g} \cdot \mathrm{L}^{-1}\right)$ & $28 \pm 4.8$ & $28 \pm 2.4$ & $25 \pm 3.5$ & $<0.001$ \\
\hline AL peak after surgery $\left(\mathrm{mmol} \cdot \mathrm{I}^{-1}\right)$ & $3.8 \pm 1.8$ & $3.6 \pm 1.4$ & $5.9 \pm 4.3$ & $<0.001$ \\
\hline Acute Renal Failure & $9.7 \%(272)$ & $6.5 \%(174)$ & $61.6 \%(98)$ & $<0.001$ \\
\hline Need for RRT & $2.1 \%(58)$ & $0.8 \%(22)$ & $22.6 \%(36)$ & $<0.001$ \\
\hline Haemorrhage-related reexploration & $3.4 \%(97)$ & $3 \%(81)$ & $10.1 \%(16)$ & $<0.001$ \\
\hline Pericardial tamponade & $0.7 \%(19)$ & $0.6 \%(17)$ & $1.3 \%(2)$ & 0.29 \\
\hline Drainage loss first $12 \mathrm{~h}(\mathrm{ml})$ & $392 \pm 295$ & $386 \pm 287$ & $492 \pm 398$ & $<0.001$ \\
\hline Re-exploration & $1.6 \%(47)$ & $1.1 \%(30)$ & $10.7 \%(17)$ & $<0.001$ \\
\hline Need for blood products first $24 \mathrm{~h}$ (Units) & $1.2 \pm 1.9$ & $1.1 \pm 1.6$ & $3.2 \pm 3.9$ & 0.01 \\
\hline Stroke & $1.4 \%(39)$ & $1.1 \%(28)$ & $6.9 \%(11)$ & $<0.001$ \\
\hline Septicaemia & $6.6 \%(186)$ & $4.6 \%(122)$ & $40.2 \%(65)$ & $<0.001$ \\
\hline Mean ICU stay (hours) & $125 \pm 158$ & $114 \pm 131$ & $301 \pm 314$ & 0.003 \\
\hline Mean hospital stay (days) & $25.0 \pm 20.3$ & $22.3 \pm 18.3$ & $36.4 \pm 58.2$ & $<0.001$ \\
\hline
\end{tabular}

BMI Body Mass Index, COPD Chronic Obstructive Pulmonary Disease, NYHA New York Heart Association classification, LVEF Left ventricular ejection fraction, PAP Pulmonary arterial pressure, EuroSCORE European system for cardiac operative risk evaluation, CABG coronary artery bypass graft, CPB Cardiopulmonary Bypass, ACC Aortic cross clamping, APACHE Acute Physiology and Chronic Health Evaluation, SAPS Simplified Acute Physiology Score, PaO2/FiO2 Arterial partial pressure of $\mathrm{O} 2$ and fraction of inspired oxygen ratio, LCOS Low Cardiac Output Syndrome, PMI Perioperative Myocardial Infarction, IABP intra-aortic balloon pump, AL Arterial Lactate, RRT Renal Replacement Therapy. Results are expressed as mean \pm standard deviation, percentage or median and interquartile range

Postoperative SAL was measured $24 \mathrm{~h}$ after CS and patients were classified into different categories based on local laboratory categories of SAL and previous research $[4,6]$ : normal $\left(\geq 35 \mathrm{~g} \cdot \mathrm{L}^{-1}\right)(n=162)$, low deficit $(30-34.9$ $\left.\mathrm{g} \cdot \mathrm{L}^{-1}\right)(n=924)$, mild deficit $\left(25-29.9 \mathrm{~g} \cdot \mathrm{L}^{-1}\right)(n=1249)$ and severe deficit $\left(<25 \mathrm{~g} \cdot \mathrm{L}^{-1}\right)(n=483)$. We chose $24 \mathrm{~h}$ postoperative for measuring SAL because based on our clinical experience unstable patients received usually major part of fluid resuscitation and blood products from ICU admission to $24 \mathrm{~h}$, which may alter SAL the most, and because $24 \mathrm{~h}$ is the timeline used in ICU for prognosis assessment [16].

Recent acute myocardial infarction (AMI) was defined as an AMI that required admission to the hospital during the last month before surgery or an AMI that did not allow discharge from the hospital before surgery. The other definitions used for this study were based on the Society of Thoracic Surgeons' national CS database definitions [17].

The operations were performed by the same group of surgeons during the study period following standards of practice. The priming fluid for the CPB system were crystalloids during the study period with a priming volume of the circuit between 500 and 800 $\mathrm{mL}$. In all patients, decisions regarding perioperative management were made by the attending physician according to local protocols. Patients were treated according to hemodynamic parameters and metabolic markers of tissue perfusion, such as arterial lactate 
levels and venous oxygen saturation. Fluid resuscitation was performed based on local protocol following a restricted fluid regimen in order to avoid excessive positive fluid balance (i.e., $>2 \mathrm{~L}$ of positive fluid balance per day) [18]. Our hemodynamic objectives were to achieve both appropriate mean arterial pressure (MAP) (i.e., about $70 \mathrm{mmHg}$ or the previously reported usual MAP in each patient) and urine output (i.e., $>0.5 \mathrm{~mL} \cdot \mathrm{Kg}^{-1} \cdot \mathrm{h}^{-1}$ or higher to avoid positive fluid balance). Global end-diastolic volume index (about $680-800 \mathrm{~mL} \cdot \mathrm{m}^{-2}$ ) or cardiac index (about 2.5 $\mathrm{L} \cdot \mathrm{min}^{-1} \cdot \mathrm{m}^{-2}$ ) were also monitored in the presence of high dose of vasopressors or inotropes [19]. We monitored central venous pressure to see the dynamic changes over time and fluid responsiveness to passive leg raise in conjunction with previous clinical evaluation for hemodynamic management [19]. Fluid loading was performed by crystalloids. According with our previous research, our perioperative transfusion trigger is hemoglobin value between 7 and $8 \mathrm{~g} \cdot \mathrm{dL}^{-1}$ with a targeted hematocrit on CPB about 21-24\% [20]. Transfusions occurring during fist $24 \mathrm{~h}$ were assessed due to the potential influence over SAL. Supplemental albumin administration was not specifically forbidden but none was administered to any patient during the study period. A glycemic protocol was applied during and after CS based on local protocols in order to avoid blood glucose levels $>180 \mathrm{mg} \cdot \mathrm{dL}^{-1}$ during and/ or after CS.

\section{Statistical analyses}

Statistical analysis was conducted using PASW statistics 20.0 (SPSS Inc., Chicago, Illinois, USA). Data are expressed as mean \pm standard deviation or median (interquartile range) as appropriate. In order to evaluate the association of postoperative SAL with mortality after CS, we analyzed differences between survivors and non-survivors with univariate analyses (for comparisons between groups the Mann-Whitney $\mathrm{U}$ test was used or, when appropriate, the two-sample t-test; the $x^{2}$-test was used to evaluate categorical prognostic factors) to identify the importance of postoperative SAL as a factor associated with mortality. ANOVA was used to compare differences in characteristics and outcome between different hypoalbuminemia subgroups ( $P$ values shown in tables) and subsequent post hoc tests (Bonferroni tests) were used to determine and confirm significant differences in the various pairwise comparisons ( $P$ values shown in results section).

Multivariate analysis was carried out using a backward stepwise logistic regression to identify predictors of inhospital mortality after CS. Variables with $P<0.1$ were included in the initial model and according the criteria of the investigators (i.e., redundant and associated variables were avoided). Change-in-estimates criterion and backwards deletion with a $10 \%$ cutoff was used to eliminate confounding variables from our final models. Proportional Hazards Cox regression model was used to evaluate predictors of long-term mortality after adjusting for the time of follow-up period.

We tested for interactions between the variables that we introduced into all the multivariate analyses, in order to avoid destabilization of the different analyses. We performed adjustment for age, preoperative albumin, type of cardiac surgery, CPB time, EuroSCORE and the significant preoperative differences between the subgroups in order to avoid the influence of the severity of illness when outcomes were analyzed. Finally, we also analyze using the same statistical methods preoperative and intraoperative variables in order to show factors associated with the occurrence of postoperative moderate to severe hypoalbuminemia.

Table 2 Multivariate analysis - variables associated with in-hospital and long-term mortality

\begin{tabular}{lll}
\hline Dependent variable in-hospital mortality & $\begin{array}{l}\text { Odds ratio } \\
(95 \% \text { Confidence Interval })\end{array}$ \\
Age & $1.050(1.027-1.075)$ & $<\mathbf{0 . 0 0 1}$ \\
Cardiopulmonary bypass time $(>100 \mathrm{~min})$ & $1.007(1.003-1.010)$ & $\mathbf{0 . 0 0 1}$ \\
Albumin $24 \mathrm{~h}$ after surgery $\left(\mathrm{g} \cdot \mathrm{L}^{-1}\right)$ & $0.844(0.805-0.844)$ & $\mathbf{0 . 0 0 7}$ \\
Dependent variable long-term mortality & Hazards ratio & $\mathbf{P}$ \\
& $(95 \%$-value \\
Age & $1.063(1.049-1.076)$ & $<\mathbf{0 . 0 0 1}$ \\
Cardiopulmonary bypass time $(>100 \mathrm{~min})$ & $1.004(1.002-1.006)$ & $\mathbf{0 . 0 0 1}$ \\
Dilated cardiomyopathy & $1.435(1.139-1.810)$ & $\mathbf{0 . 0 0 2}$ \\
Albumin $24 \mathrm{~h}$ after surgery $\left(\mathrm{g} \cdot \mathrm{L}^{-1}\right)$ & $0.846(0.821-0.871)$ & $<\mathbf{0 . 0 0 1}$ \\
Acute Renal Failure & $2.523(1.395-2.933)$ & $\mathbf{0 . 0 0 1}$ \\
Low Cardiac Output Syndrome & $1.489(1.276-1.656)$ & $\mathbf{0 . 0 0 6}$ \\
Septicaemia & $1.125(1.018-1.696)$ & $\mathbf{0 . 0 2}$ \\
\hline
\end{tabular}




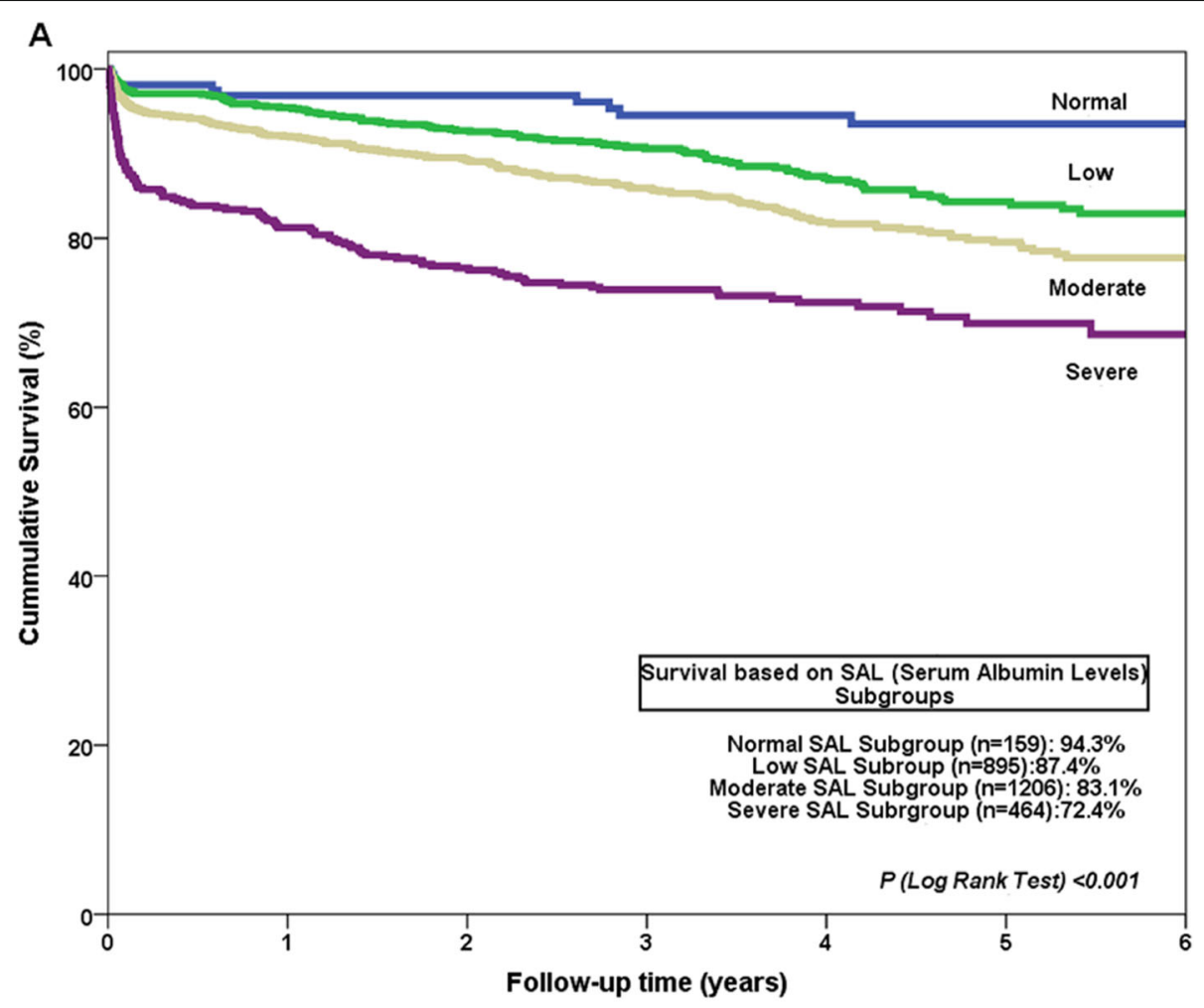

B

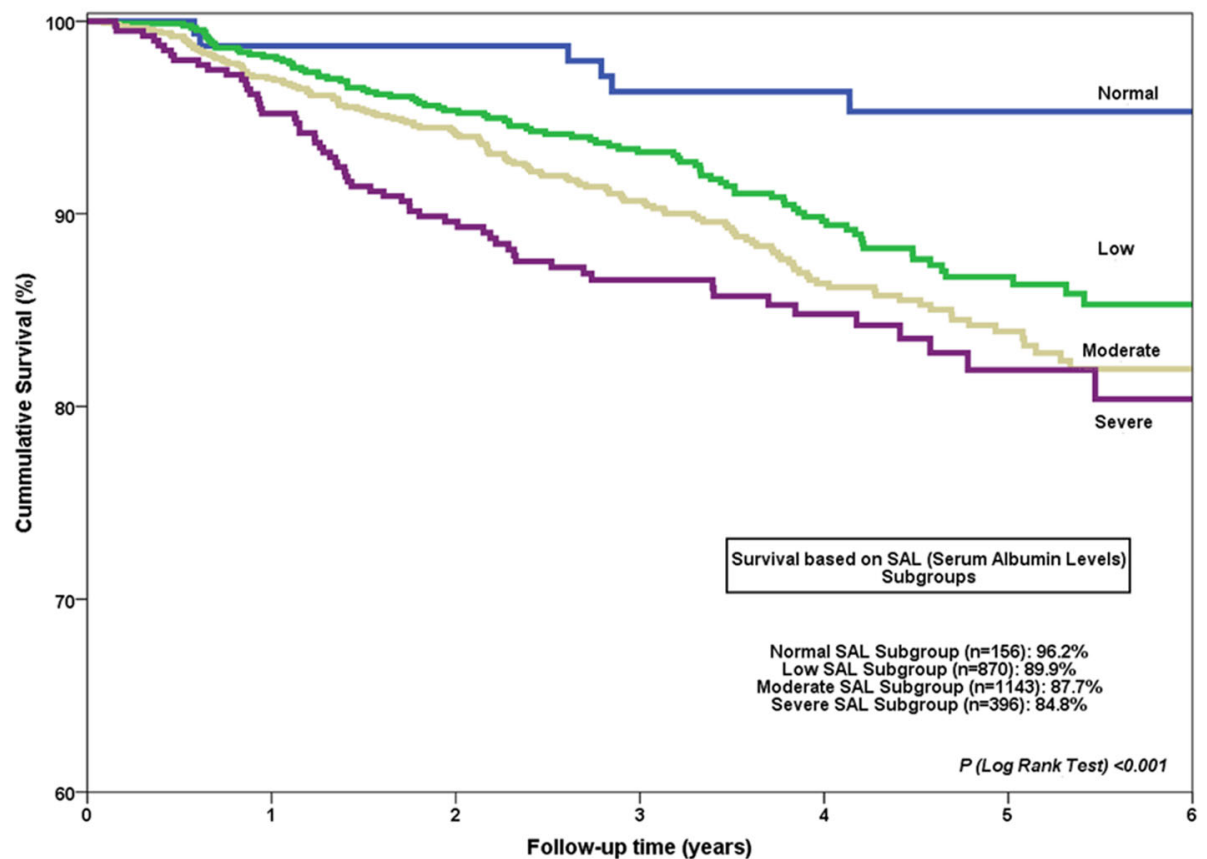

Fig. 1 Kaplan-Meier survival curves based on subgroups of patients with different albumin levels $24 \mathrm{~h}$ after cardiac surgery including in-hospital mortality (a) and only with hospital survivors (b)

In all cases, the Kolmogorov-Smirnov test and D'Agostino-Pearson omnibus normality test were used to check the normal distribution of our population and to assess the goodness-of-fit of the final regression models. Survival analysis was carried out using the Kaplan-Meier estimator for the different 
hypoalbuminemia subgroups. Proportional Hazards Cox regression model was used to confirm survival analysis, which was risk-adjusted in order to avoid the severity of illness. Two-tailed $P$ value $<0.05$ was considered statistically significant.

\section{Results}

Baseline characteristics and postoperative SAL as a factor associated with mortality and survival

Patients were 2818 and overall they had a hospital mortality of $5.6 \%$. Characteristics of our studied population are provided in Table 1 . Preoperative, intraoperative and postoperative data comparing survivors and non-survivors showed that non-survivors were older, underwent longer $\mathrm{CPB}$ during CS, had lower SAL and higher rates of morbidities and postoperative complications (see Table 1). Multivariate analysis showed that lower levels of SAL (i.e., SAL as absolute value) were both associated with increased in-hospital (Odds ratio (OR): 0.844, 95\% confidence interval (CI) 0.805 to $0.844, P=0.007$ ) and long-term mortality (Hazard ratio (HR): $0.846,95 \%$ CI 0.821 to $0.871, P<$ $0.001)$. Other variables, such as older age, having a dilated cardiomyopathy in the preoperative echocardiography, suffering a CPB $>100 \mathrm{~min}$, suffering from postoperative acute renal failure, low cardiac output syndrome and sepsis during the postoperative period, were also associated with mortality (Table 2; see Supplementary Table 1 for full model results).

A follow-up was performed in all patients for inhospital mortality in 2659 patients with a mean follow-up of $4.6 \pm 2.4$ years. There was shown a lower survival rate and higher mortality over time in patients with lower SAL, and particularly in the severe albumin deficit group (Fig. 1 and Table 3). Additional analyses showed that normal SAL $(\geq 35$ $\left.\mathrm{g} \cdot \mathrm{L}^{-1}\right)$ was associated with better in-hospital survival $(\mathrm{HR}=0.570,95 \% \mathrm{CI} 0.388$ to $0.836, P=0.004)$ and long term survival $(\mathrm{HR}=0.315,95 \% \mathrm{CI} 0.145$ to
0.682, $P=0.003)$ whereas moderate $\left(25-29.9 \mathrm{~g} \cdot \mathrm{L}^{-1}\right)$ $(\mathrm{HR}=1.604,95 \% \mathrm{CI} 1.452$ to $1.806, P=0.001)$ and severe deficits $\left(<25 \mathrm{~g} \cdot \mathrm{L}^{-1}\right) \quad(\mathrm{HR}=1.966, \quad 95 \% \quad \mathrm{CI}$ 1.520 to $2.853, P=0.001)$ were independent risk factors for increased long-term mortality. The relationship between postoperative SAL and in-hospital mortality was not linear and progressively higher among subgroups depending on the severity of hypoalbuminemia, as showed by Fig. 2 .

\section{Differences between postoperative SAL subgroups and risk factors for hypoalbuminemia}

When we compared between postoperative SAL subgroups $(P$ from ANOVA test provided in Table 4), preoperative variables showed older patients, higher cardiovascular risk factors (such as hypertension, dyslipidemia and diabetes mellitus) and an increased prevalence of chronic renal insufficiency in low SAL determination groups (Bonferroni post hoc test; $P<0.001)$. In addition, there was subgroup differences in hemoglobin determinations before surgery $(P=0.001)$. Patients with severe SAL deficit required longer $\mathrm{CPB}$ and aortic cross clamping (ACC) times compared with the other groups $(P<0.001)$. Postoperative variables showed longer ventilation time and vasoactive drug requirements for low SAL subgroups $(P<0.001)$ and a higher acute renal failure incidence in the severe SAL deficit group when compared with other subgroups $(P<0.001)$. Mean ICU and hospital stay was higher for the low SAL determination groups, especially in the severe deficit group $(P<0.001)$. In-hospital mortality was also higher in this group when compared to others $(P<0.001)$.

All these findings regarding the differences in outcomes between the SAL subgroups from the univariate analysis were analyzed by means of multivariate analysis. A higher mortality rate, longer ICU stay and higher incidence of bleeding and sepsis-related complications were

Table 3 Long-term mortality based on subgroups of patients with different albumin levels $24 \mathrm{~h}$ after cardiac surgery including all patients (A) and only with hospital survivors (B)

\begin{tabular}{|c|c|c|c|c|}
\hline A & In-hospital survival & 1-year survival & 3-year survival & 5-year survival \\
\hline Normal Levels $\left(\geq 35 \mathrm{~g} \cdot \mathrm{L}^{-1}\right)$ & $98.1 \%$ & $98.1 \%$ & $96.5 \%$ & $94.3 \%$ \\
\hline Low deficit (30-34.9 $\left.\mathrm{g} \cdot \mathrm{L}^{-1}\right)$ & $97.3 \%$ & $94.2 \%$ & $89.2 \%$ & $87.4 \%$ \\
\hline Mild deficit $\left(25-29.9 \mathrm{~g} \cdot \mathrm{L}^{-1}\right)$ & $95 \%$ & $91.5 \%$ & $86.1 \%$ & $83.1 \%$ \\
\hline Severe deficit $\left(<25 \mathrm{~g} \cdot \mathrm{L}^{-1}\right)$ & $85.9 \%$ & $78.3 \%$ & $74.5 \%$ & $72.4 \%$ \\
\hline \multicolumn{5}{|l|}{ B } \\
\hline Normal Levels ( $\left.\geq 35 \mathrm{~g} \cdot \mathrm{L}^{-1}\right)$ & $100 \%$ & $98.9 \%$ & $97.8 \%$ & $96.2 \%$ \\
\hline Low deficit (30-34.9 g. $\left.\mathrm{L}^{-1}\right)$ & $100 \%$ & $97.9 \%$ & $94.2 \%$ & $89.9 \%$ \\
\hline Mild deficit $\left(25-29.9 \mathrm{~g} \cdot \mathrm{L}^{-1}\right)$ & $100 \%$ & $96.8 \%$ & $92.3 \%$ & $87.7 \%$ \\
\hline Severe deficit $\left(<25 \mathrm{~g} \cdot \mathrm{L}^{-1}\right)$ & $100 \%$ & $95.1 \%$ & $87.5 \%$ & $84.8 \%$ \\
\hline
\end{tabular}


A

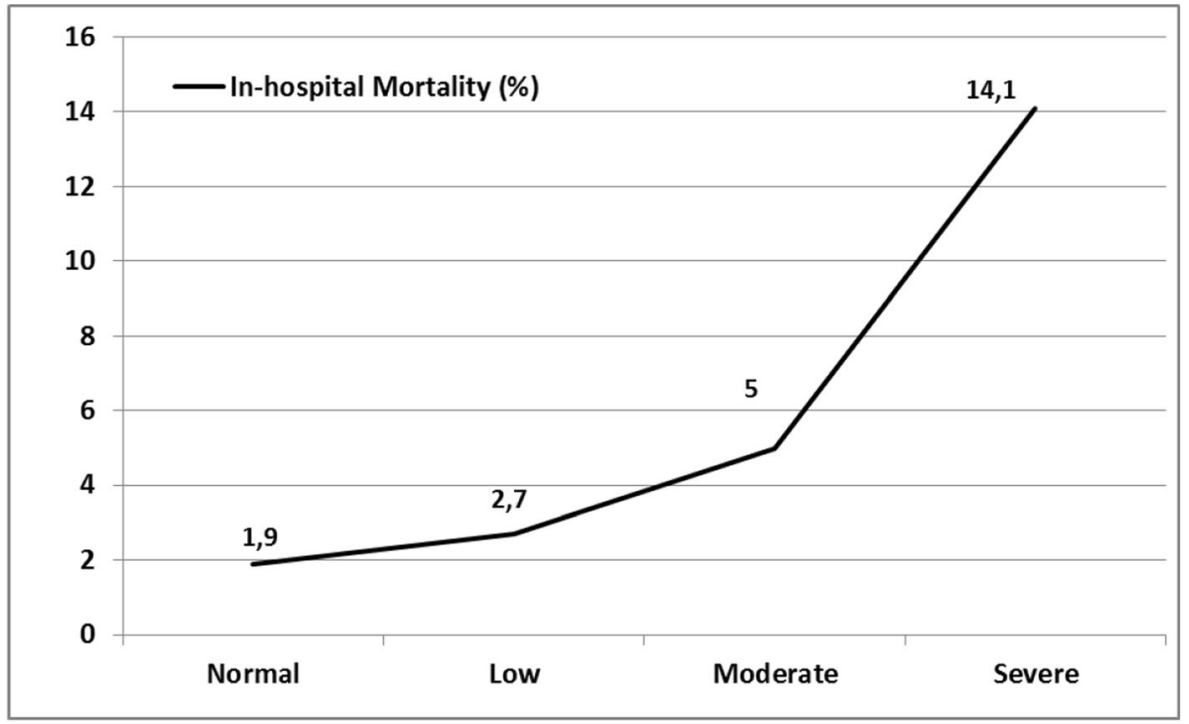

B

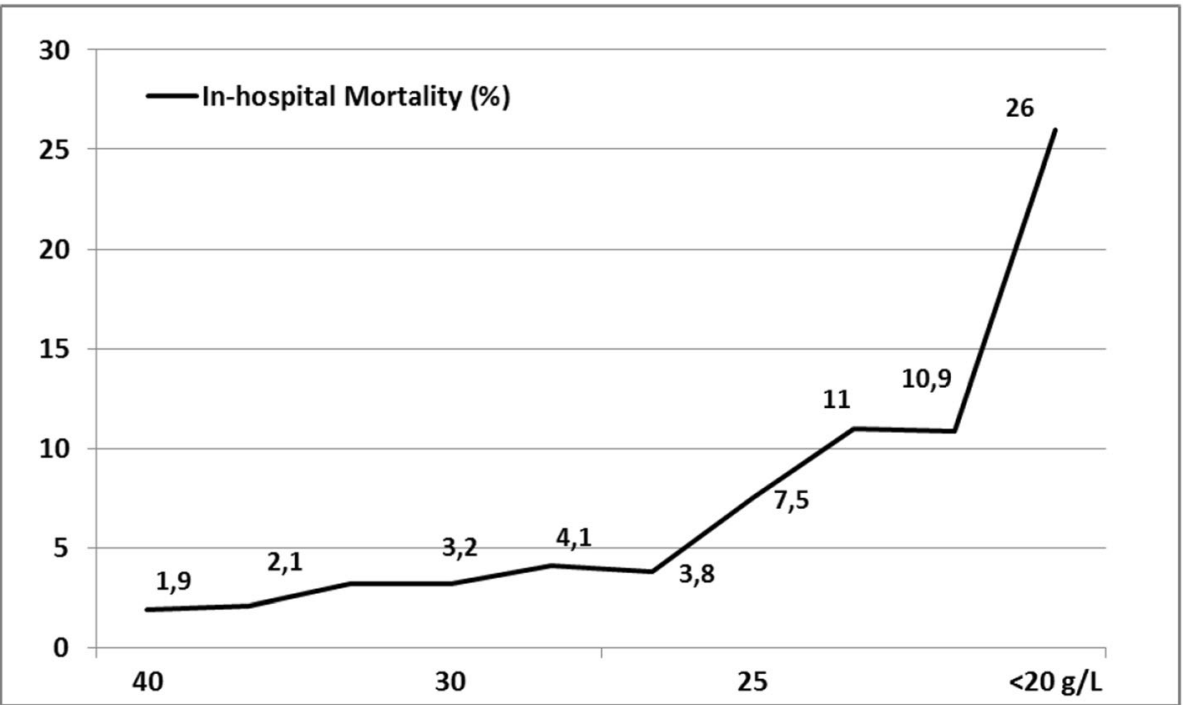

Fig. 2 Relationship between in-hospital mortality rates and postoperative Serum Albumin Levels based on subgroups (a) and degree of hypoalbuminemia (b)

associated with lower levels of postoperative SAL when we made comparisons between the different postoperative SAL subgroups (Table 5; see Supplementary Table 2 for full model results).

We also identified an association between chronic renal insufficiency, past $\mathrm{CS}$ and longer $\mathrm{CPB}$ times with the presence of mild to severe degree of hypoalbuminaemia at $24 \mathrm{~h}$ after CS (Table 6; see Supplementary Table 3 for full model results).

\section{Discussion}

The most important finding of the current study is the association of postoperative hypoalbuminemia with worst outcomes after CS depending on its intensity, even with influence in long-term scenario. To the best of our knowledge this is the only prospective study addressing the role of postoperative SAL in most types of CS procedures under the effect of $\mathrm{CPB}$, even those with moderate to high complexity [12].

We excluded patients with low preoperative SAL because this may reflect a poor nutritional status that influences our results [2]. Several studies used different preoperative values as markers, making it difficult to determine a specific point to correlate these levels and a repercussion over time [8-10]. Despite the different values considered among these studies, it has been 
Table 4 Preoperative (A), intraoperative and postoperative (B) variables of subgroups of patients with different albumin levels $24 \mathrm{~h}$ after cardiac surgery

\begin{tabular}{|c|c|c|c|c|c|}
\hline A & $\begin{array}{l}\text { Normal Levels }\left(\geq 35 \mathrm{~g} \cdot \mathrm{L}^{-1}\right) \\
\mathrm{n}=162 \\
5.8 \%\end{array}$ & $\begin{array}{l}\text { Low deficit } \\
\left(30-34.9 \mathrm{~g} \cdot \mathrm{L}^{-1}\right) \\
n=924 \\
32.8 \%\end{array}$ & $\begin{array}{l}\text { Mild deficit } \\
\left(25-29.9 \mathrm{~g} \cdot \mathrm{L}^{-1}\right) \\
\mathrm{n}=1249 \\
44.3 \%\end{array}$ & $\begin{array}{l}\text { Severe deficit }\left(<25 \mathrm{~g} \cdot \mathrm{L}^{-1}\right) \\
\mathrm{n}=483 \\
17.1 \%\end{array}$ & $\begin{array}{l}\text { ANOVA } \\
P \text { value }\end{array}$ \\
\hline Sex (male) & $75 \%(122)$ & $68 \%(634)$ & $61 \%(765)$ & $57 \%(278)$ & 0.001 \\
\hline Age (years) & $57 \pm 14.1$ & $63 \pm 11.6$ & $65.5 \pm 11.2$ & $67.7 \pm 10$ & $<0.001$ \\
\hline Albumin before surgery (g $\cdot L-1)$ & $41 \pm 2.5$ & $41 \pm 2.8$ & $39 \pm 2.9$ & $39 \pm 2.2$ & 0.78 \\
\hline Subjective Global Assessment (class B) & $6.1 \%(10)$ & $5.9 \%(55)$ & $58.8 \%(73)$ & $5.1 \%(25)$ & 0.89 \\
\hline Hypertension & $53.0 \%(86)$ & $60.4 \%(558)$ & $63.4 \%(792)$ & $68.7 \%(332)$ & 0.001 \\
\hline Dyslipidemia & $42.0 \%(68)$ & $47.6 \%(440)$ & $53.1 \%(663)$ & $52.2 \%(252)$ & 0.009 \\
\hline Diabetes Mellitus & $19.1 \%(31)$ & $24.3 \%(225)$ & $26.1 \%(327)$ & $27.1 \%(131)$ & 0.06 \\
\hline $\mathrm{BMI}\left(\mathrm{kg} \cdot \mathrm{m}^{-2}\right)$ & $27.6 \pm 4.6$ & $28.3 \pm 4.2$ & $27.9 \pm 4.2$ & $27.4 \pm 4.3$ & 0.90 \\
\hline Peripheral vascular disease & $3.7 \%(6)$ & $6.8 \%(63)$ & $10.2 \%(127)$ & $11 \%(53)$ & 0.001 \\
\hline Chronic renal insufficiency & $2.5 \%(4)$ & $2.9 \%(27)$ & $5.2 \%(65)$ & $10.4 \%(50)$ & $<0.001$ \\
\hline Renal Failure (on Dialysis) & $0.6 \%(1)$ & $0.4 \%(4)$ & $0.7 \%(9)$ & $1.9 \%(9)$ & 0.04 \\
\hline Creatinine before surgery $\left(\mu \mathrm{mol} \cdot \mathrm{I}^{-1}\right)$ & $86 \pm 36$ & $88 \pm 34$ & $96 \pm 61$ & $110 \pm 84$ & 0.001 \\
\hline Previous Stroke & $2.5 \%(4)$ & $5.4 \%(50)$ & $5.4 \%(68)$ & $7.5 \%(36)$ & 0.99 \\
\hline COPD & $8 \%(13)$ & $11.8 \%(109)$ & $12.4 \%(155)$ & $12.4 \%(60)$ & 0.43 \\
\hline Active smokers & $19.1 \%(31)$ & $15.9 \%(147)$ & $14.9 \%(187)$ & $14.9 \%(72)$ & 0.42 \\
\hline Previous Atrial Fibrillation & $25.9 \%(42)$ & $24 \%(222)$ & $23 \%(288)$ & $24.6 \%(119)$ & 0.59 \\
\hline Previous Myocardial Infarction & $14.2 \%(23)$ & $14.7 \%(136)$ & $16 \%(200)$ & $16.1 \%(78)$ & 0.79 \\
\hline Recent Myocardial Infarction & $4.9 \%(8)$ & $7.7 \%(71)$ & $11.8 \%(148)$ & $17.2 \%(83)$ & 0.001 \\
\hline On B-Blockers & $34.6 \%(56)$ & $41.2 \%(381)$ & $41.6 \%(520)$ & $43.1 \%(208)$ & 0.82 \\
\hline On statins & $30.2 \%(49)$ & $40.3 \%(372)$ & $43.3 \%(541)$ & $41 \%(198)$ & 0.01 \\
\hline On Aspirin & $28.4 \%(46)$ & $42.2 \%(390)$ & $47.6 \%(594)$ & $46.2 \%(223)$ & 0.001 \\
\hline On diuretics & $47.5 \%(77)$ & $45.1 \%(417)$ & $48.7 \%(608)$ & $49.3 \%(238)$ & 0.33 \\
\hline Hypertrophic cardiomyopathy & $27.1 \%(44)$ & $31.6 \%(292)$ & $32.9 \%(412)$ & $27.3 \%(132)$ & 0.11 \\
\hline Dilated cardiomyopathy & $27.1 \%(44)$ & $23 \%(213)$ & $19.3 \%(242)$ & $16.1 \%(78)$ & 0.02 \\
\hline LVEF (\%) & $60(48-72)$ & $61(47-75)$ & $60(41-79)$ & $60(43-77)$ & 0.34 \\
\hline PAP $(\mathrm{mmHg})$ & $48(37-59)$ & $32(21-43)$ & $37(21-53)$ & $35(18-52)$ & 0.26 \\
\hline Hemoglobin before surgery $\left(\mathrm{g} \cdot \mathrm{dL}^{-1}\right)$ & $13.5 \pm 1.5$ & $13.3 \pm 1.6$ & $12.9 \pm 1.7$ & $12.4 \pm 1.8$ & 0.001 \\
\hline Platelet count before surgery $\left(1 \cdot \mathrm{nL}^{-1}\right)$ & $203 \pm 49$ & $213 \pm 67$ & $215 \pm 68$ & $224 \pm 75$ & 0.002 \\
\hline Past Cardiac surgery & $12.3 \%(20)$ & $9.4 \%(87)$ & $9.1 \%(114)$ & $9.3 \%(45)$ & 0.62 \\
\hline Emergent Surgery & $0.6 \%(1)$ & $0.9 \%(8)$ & $4.6 \%(58)$ & $15.7 \%(76)$ & $<0.001$ \\
\hline EurOSCORE & $5.2 \pm 3.2$ & $5.7 \pm 2.8$ & $6.2 \pm 1.9$ & $7.3 \pm 3.2$ & 0.14 \\
\hline Parsonnet score & $11.0 \pm 6.2$ & $11.1 \pm 5.2$ & $12.8 \pm 3.7$ & $13.4 \pm 2.8$ & 0.25 \\
\hline Mean Pre-ICU stay (days) & $1.1 \pm 0.3$ & $1.1 \pm 0.4$ & $1.0 \pm 0.3$ & $1.9 \pm 2.1$ & 0.02 \\
\hline B & $\begin{array}{l}\text { Normal Levels } \\
\left(\geq 35 \mathrm{~g} \cdot \mathrm{L}^{-1}\right) \\
\mathrm{n}=162 \\
5.8 \%\end{array}$ & $\begin{array}{l}\text { Low deficit } \\
\left(30-34.9 \mathrm{~g} \cdot \mathrm{L}^{-1}\right) \\
\mathrm{n}=924 \\
32.8 \%\end{array}$ & $\begin{array}{l}\text { Mild deficit }\left(25-29.9 \mathrm{~g} \cdot \mathrm{L}^{-1}\right) \\
\mathrm{n}=1249 \\
44.3 \%\end{array}$ & $\begin{array}{l}\text { Severe deficit }\left(<25 g \cdot L^{-1}\right) \\
n=483 \\
17.1 \%\end{array}$ & $\begin{array}{l}\text { ANOVA } \\
P \text { value }\end{array}$ \\
\hline \multicolumn{6}{|l|}{ Intraoperative data } \\
\hline Isolated CABG & $20.4 \%(33)$ & $32.3 \%(298)$ & $32.5 \%(406)$ & $35.2 \%(170)$ & 0.001 \\
\hline Isolated valve surgery & $64.2 \%(104)$ & $56.5 \%(522)$ & $50 \%(624)$ & $42.7 \%(206)$ & 0.001 \\
\hline$C A B G+$ valve surgery & $3.1 \%(5)$ & $4.9 \%(45)$ & $8.6 \%(107)$ & $7.7 \%(37)$ & 0.001 \\
\hline Other cardiac surgery & $12.3 \%(20)$ & $6.4 \%(59)$ & $9 \%(112)$ & $14.5 \%(70)$ & 0.001 \\
\hline Number of bypass & $2(2-3)$ & $2(2-3)$ & $2(2-3)$ & $2(2-4)$ & 0.85 \\
\hline CPB time (min) & $95 \pm 39$ & $105 \pm 35$ & $114 \pm 41$ & $127 \pm 47$ & $<0.001$ \\
\hline
\end{tabular}


Table 4 Preoperative (A), intraoperative and postoperative (B) variables of subgroups of patients with different albumin levels $24 \mathrm{~h}$ after cardiac surgery (Continued)

\begin{tabular}{|c|c|c|c|c|c|}
\hline ACC time (min) & $65 \pm 30$ & $69 \pm 27$ & $75 \pm 29$ & $81 \pm 32$ & $<0.001$ \\
\hline \multicolumn{6}{|l|}{ Postoperative data } \\
\hline APACHE ॥ & $12.2 \pm 2.2$ & $11.9 \pm 3.1$ & $12.5 \pm 5.8$ & $12.9 \pm 4.3$ & 0.15 \\
\hline APACHE III & $53.1 \pm 17.9$ & $49.2 \pm 11.5$ & $68.1 \pm 20.6$ & $75.9 \pm 26.8$ & $<0.001$ \\
\hline SAPS $\|$ & $24 \pm 8.6$ & $22.3 \pm 8.2$ & $25.8 \pm 12.4$ & $28.2 \pm 14.6$ & 0.01 \\
\hline SAPS III & $39.5 \pm 8.4$ & $38.2 \pm 8.5$ & $43.2 \pm 10.5$ & $45.3 \pm 12.6$ & $<0.001$ \\
\hline Ventilation time (hours) & $6(4-8)$ & $19.5(11.5-30.5)$ & $18(0-72)$ & $21(0-242)$ & $<0.001$ \\
\hline $\mathrm{PaO} 2 / \mathrm{FiO} 2$ ratio on admission & $323 \pm 91$ & $330 \pm 95$ & $336 \pm 96$ & $319 \pm 110$ & 0.21 \\
\hline $\mathrm{PaO} 2 / \mathrm{FiO} 2$ ratio $12 \mathrm{~h}$ after admission & $338 \pm 87$ & $319 \pm 83$ & $310 \pm 90$ & $290 \pm 95$ & $<0.001$ \\
\hline $\mathrm{PaO} 2 / \mathrm{FiO} 2$ ratio $24 \mathrm{~h}$ after admission & $328 \pm 72$ & $318 \pm 67$ & $306 \pm 76$ & $284 \pm 89$ & $<0.001$ \\
\hline Reintubation & 0 & $0.5 \%(5)$ & $1.6 \%(20)$ & $1.2 \%(6)$ & 0.10 \\
\hline Tracheostomy & $0.6 \%(1)$ & $0.6 \%(6)$ & $1.1 \%(14)$ & $2.8 \%(14)$ & 0.09 \\
\hline AL peak after surgery $\left(\mathrm{mmol} \cdot \mathrm{I}^{-1}\right)$ & $3.5 \pm 1.3$ & $3.7 \pm 1.7$ & $3.7 \pm 1.7$ & $4.2 \pm 2.3$ & 0.001 \\
\hline Need of vasoactive drugs (hours) & $67 \pm 92$ & $75 \pm 112$ & $101 \pm 139$ & $152 \pm 173$ & $<0.001$ \\
\hline LCOS & $17.3 \%(28)$ & $28.3 \%(262)$ & $44.9 \%(562)$ & $65.8 \%(318)$ & $<0.001$ \\
\hline PMI & $8 \%(13)$ & $9.1 \%(84)$ & $11.8 \%(147)$ & $17.2 \%(83)$ & $<0.001$ \\
\hline IABP support & $0.6 \%(1)$ & $4.3 \%(40)$ & $7.4 \%(93)$ & $18.2 \%(88)$ & 0.001 \\
\hline Atrial Fibrillation & $33.3 \%(54)$ & $34.4 \%(318)$ & $40.3 \%(503)$ & $49.5 \%(239)$ & 0.001 \\
\hline Acute Renal Failure & $3.1 \%(5)$ & $4.4 \%(41)$ & $9.7 \%(121)$ & $21.7 \%(105)$ & $<0.001$ \\
\hline Need for RRT & 0 & $0.4 \%(4)$ & $1.8 \%(22)$ & $6.6 \%(32)$ & $<0.001$ \\
\hline Haemorrhage-related reexploration & 0 & $1.3 \%(12)$ & $4.2 \%(52)$ & $6.8 \%(33)$ & 0.001 \\
\hline Pericardial tamponade & 0 & $0.2 \%(2)$ & $0.9 \%(11)$ & $1.2 \%(6)$ & 0.07 \\
\hline Drainage loss first $12 \mathrm{~h}(\mathrm{ml})$ & $307 \pm 163$ & $355 \pm 255$ & $399 \pm 298$ & $472 \pm 369$ & 0.33 \\
\hline Re-exploration & $1.2 \%(2)$ & $0.5 \%(5)$ & $1.8 \%(23)$ & $3.2 \%(17)$ & 0.07 \\
\hline Need for blood products first $24 \mathrm{~h}$ (Units) & $1(0-2)$ & $1(0-6)$ & $1(0-3)$ & $1(0-4)$ & 0.08 \\
\hline Stroke & $0.6 \%(1)$ & $1 \%(9)$ & $1.8 \%(22)$ & $1.4 \%(7)$ & 0.38 \\
\hline Septicaemia & $2.4 \%(4)$ & $3.1 \%(29)$ & $6.4 \%(81)$ & $14.9 \%(72)$ & $<0.001$ \\
\hline Mean ICU stay (hours) & $158 \pm 213$ & $190 \pm 270$ & $274 \pm 315$ & $327 \pm 377$ & 0.001 \\
\hline Mean hospital stay (days) & $18 \pm 11$ & $21 \pm 14$ & $26 \pm 21$ & $33 \pm 30$ & 0.001 \\
\hline In-hospital mortality & $1.9 \%(3)$ & $2.7 \%(25)$ & $5 \%(63)$ & $14.1 \%(68)$ & $<0.001$ \\
\hline
\end{tabular}

$B M I$ Body Mass Index, COPD Chronic Obstructive Pulmonary Disease, NYHA New York Heart Association classification, LVEF Left ventricular ejection fraction, $P A P$ Pulmonary arterial pressure; EuroSCORE European system for cardiac operative risk evaluation, $C A B G$ coronary artery bypass graft; $C P B$ cardiopulmonary bypass, ACC Aortic cross clamping, APACHE Acute Physiology and Chronic Health Evaluation, SAPS Simplified Acute Physiology Score, $\mathrm{PaO2} / \mathrm{FiO} 2$ Arterial partial pressure of O2 and fraction of inspired oxygen ratio, LCOS Low Cardiac Output Syndrome, PMI Perioperative Myocardial Infarction, IABP intra-aortic balloon pump, AL Arterial Lactate, RRT Renal Replacement Therapy. Results are expressed as mean \pm standard deviation, percentage or median and interquartile range

shown that patients with low preoperative SAL have an increased risk of morbidities and mortality after surgery [5-11]. The need for reoperation due to bleeding has been shown to be over $32 \%$ and mortality about $36.2 \%$ in patients with low SAL [3]. Preoperative $\mathrm{SAL}<25 \mathrm{~g} \cdot \mathrm{L}^{-1}$ has been associated with higher mortality risk (OR 2.0; 95\% CI, 1.3-3.0; $P=0.002$ ) and a higher reoperation for bleeding [4]. In addition, preoperative $\mathrm{SAL}<30 \mathrm{~g} \cdot \mathrm{L}^{-1}$ has been related with a prolonged ICU and in-hospital stay and a higher mortality compared with patients presenting normal SAL, as an independent risk factor [21]. Over the years, albumin has been considered as a negative acute-phase protein and a marker of inflammation [1], but it has not been taken into consideration to predict worse outcomes and mortality as a postoperative factor in CS. Since 1988, when it was first reported an increased risk of complications and prolonged hospital stay in elderly patients who presented preoperative low SAL [22], many other studies have been performed afterwards analyzing preoperative SAL [8-10]. Some studies have been performed showing altered protein metabolism after CS procedures, such as CABG, but no one took into consideration postoperative levels [23].

Patients undergoing CS develop a certain degree of SIRS depending on the $\mathrm{CPB}$ duration required during the intervention and other factors, such as hypothermia 
Table 5 Differences between subgroups of patients with different albumin levels $24 \mathrm{~h}$ after cardiac surgery

\begin{tabular}{lcl}
\hline & Odds ratio $(95 \% \mathrm{Cl})$ & $\boldsymbol{P}$ value \\
\hline Normal Levels $\left(\geq 35 \mathrm{~g} \cdot \mathrm{L}^{-1}\right)$ vs Low deficit $\left(30-34.9 \mathrm{~g} \cdot \mathrm{L}^{-1}\right)$ & \\
In-hospital mortality & $1.018(1.002-1.034)$ & $\mathbf{0 . 0 2}$ \\
Normal Levels $\left(\geq 35 \mathrm{~g} \cdot \mathrm{L}^{-1}\right)$ vs Mild deficit $\left(25-29.9 \mathrm{~g} \cdot \mathrm{L}^{-1}\right)$ & \\
Haemorrhage-related reexploration & $2.549(1.132-5.738)$ & $\mathbf{0 . 0 2}$ \\
Septicaemia & $1.293(1.145-1.459)$ & $\mathbf{0 . 0 0 1}$ \\
Mean ICU stay (hours) & $1.778(1.469-2.087)$ & $\mathbf{0 . 0 4}$ \\
In-hospital mortality & $2.133(1.019-3.259)$ & $\mathbf{0 . 0 3}$ \\
Normal Levels $\left(\geq 35 \mathrm{~g} \cdot \mathrm{L}^{-1}\right)$ vs Severe deficit $\left(<25 \mathrm{~g} \cdot \mathrm{L}^{-1}\right)$ & \\
Haemorrhage-related reexploration & $2.849(2.132-3.138)$ & $\mathbf{0 . 0 1}$ \\
Septicaemia & $2.025(1.805-2.103)$ & $<\mathbf{0 . 0 0 1}$ \\
Mean ICU stay (hours) & $2.045(1.690-2.235)$ & $<\mathbf{0 . 0 0 1}$ \\
In-hospital mortality & $3.206(2.693-5.458)$ & $<\mathbf{0 . 0 0 1}$ \\
Low deficit $\left(30-34.9 \mathrm{~g} \cdot \mathrm{L}^{-1}\right)$ vs Mild deficit $\left(25-29.9 \mathrm{~g} \cdot \mathrm{L}^{-1}\right)$ & \\
Haemorrhage-related reexploration & $1.240(1.122-1.350)$ & $\mathbf{0 . 0 4}$ \\
Low deficit $\left(30-34.9 \mathrm{~g} \cdot \mathrm{L}^{-1}\right)$ vs Severe deficit $\left(<25 \mathrm{~g} \cdot \mathrm{L}^{-1}\right)$ & \\
Haemorrhage-related reexploration & $1.259(0.094-0.715)$ & $\mathbf{0 . 0 0 9}$ \\
Septicaemia & $1.035(1.015-1.303)$ & $<\mathbf{0 . 0 0 1}$ \\
Mean ICU stay (hours) & $2.580(2.080-3.043)$ & $\mathbf{0 . 0 1 1}$ \\
In-hospital mortality & $1.257(1.103-1.624)$ & $\mathbf{0 . 0 0 3}$ \\
Mild deficit $\left(25-29.9 \mathrm{~g} \cdot \mathrm{L}^{-1}\right)$ & vs Severe deficit $\left(<25 \mathrm{~g} \cdot \mathrm{L}^{-1}\right)$ & \\
Septicaemia & $1.035(1.015-1.303)$ & $<\mathbf{0 . 0 0 1}$ \\
In-hospital mortality & $1.244(1.130-1.456)$ & $<\mathbf{0 . 0 0 1}$ \\
\hline
\end{tabular}

and blood transfusions, which may ultimately lead to the use of vasopressor drugs $[12,13]$. Under this inflammatory condition, vital organs, such as the liver or kidneys, can worsen their function due to cellular damage, an increased vasodilation and extracapillar filtration leading to a loss of albumin to the extravascular space [24]. Following to this process, an increased fractional synthesis of albumin appears, stimulated by a lower oncotic pressure [24]. As a result, it is not surprising that the majority of our patients developed some degree of postoperative lower SAL.

On the other hand, postoperative SAL and their implications have been studied in other clinical contexts such as sepsis and acute kidney injury (AKI) in CS. The occurrence of sepsis in patients with hypoalbuminemia has

Table 6 Multivariate analysis - dependent variable having albumin levels $<30 \mathrm{~g} \cdot \mathrm{L}^{-1} 24 \mathrm{~h}$ after cardiac surgery

\begin{tabular}{lll}
\hline & Odds ratio $(95 \% \mathrm{Cl})$ & $\boldsymbol{P}$-value \\
\hline Chronic renal insufficiency & $1.316(1.085-1.595)$ & $\mathbf{0 . 0 0 5}$ \\
Hemoglobin before surgery $\left(\mathrm{g} \cdot \mathrm{dL}^{\mathbf{1}}\right)$ & $0.860(0.633-1.088)$ & 0.21 \\
Past Cardiac surgery & $1.229(1.067-1.415)$ & $\mathbf{0 . 0 0 4}$ \\
Cardiopulmonary bypass time $(>100 \mathrm{~min})$ & $1.904(1.902-2.128)$ & $<\mathbf{0 . 0 0 1}$ \\
\hline
\end{tabular}

a close pathophysiological relationship because the correct functioning of the immune response system depends on the metabolic and nutritional status, and vice versa [25]. Higher postoperative SAL may reflect a preserved lean body mass, which is related with nutritional reserve and a more efficient metabolic state, leading to a better inflammatory and immune response to surgery [2, 25]. On the other hand, sepsis is an important risk factor for mortality after CS, which produces a sepsis-induced cardiac dysfunction per se and preoperative hypoalbuminemia, has been shown to increase the risk for infection in CS [11].

Postoperative SAL may be useful as a predictive tool because is affected by several factors related with fluid and metabolic status [12]. Older age and smaller BMI are considered risk factors for bleeding complications, which are also related to higher rates of poor nutritional status $[10,11]$. Indeed, in abdominal major surgeries, albumin drop is related to bleeding and major inflammatory response [26]. This may offer a possible explanation for the association of higher rates of sepsis and bleeding related complications, as well as the higher mortality, with lower SAL subgroups in our population.

We identified an association between chronic renal insufficiency, past CS and longer CPB times, with the presence of mild to severe degree of hypoalbuminaemia at $24 \mathrm{~h}$ after CS. A high proportion of patients with the need of a new CS suffer from heart failure, condition which severity and prognosis is closely associated with the presence of chronic inflammation and certain degree of malnutrition [27]. Chronic renal insufficiency is also associated with protein-energy wasting that leads to a similar clinical scenario [28]. Both clinical conditions, especially in the presence of chronic renal insufficiency, may be enhanced by SIRS caused by longer CPB times [28-30]. In consequence, underlying causes of hypoalbuminemia may also influence worst outcomes in SAL subgroups.

Administration of exogenous albumin in some critical scenarios has proved to be a controversial measure across different studies. In the case of sepsis and/or septic shock, the latest researches state there is no influence over shortterm or long-term mortality and that its use may provide a certain hemodynamic improvement with no effect in survival rates [31]. On the contrary, a study proved that the use of exogenous albumin has a protective effect over the onset of AKI in patients with $\mathrm{SAL}<40 \mathrm{~g} \cdot \mathrm{L}^{-1}$ who underwent CS [32]. These various range of results prove the need to further analyze and research the use and determination of albumin in critical care areas.

There are certain limitations to this study, such as being a single-center long-term observational study, increasing the risk of losing track in the follow-up of 
some patients and the uncertainty over the causes of death in some cases. We described our fluid resuscitation protocol in detail but the exact amount of fluid challenge that could have influence postoperative SAL has not been provided. On the other hand, it presents several strengths. First, it is a prospective study in a large tertiary referral hospital, with a high level of complexity and a variety of all types of CS. In addition, we showed a large sample size that was further analyzed with systematic risk assessment, using preoperative and postoperative scores. Our study showed the importance of a proper stratification in patients undergoing CS. In addition, we have shown the risk profile of our CS population that may allow future comparisons with other series of CS patients, which is of great importance since the widespread use and importance of risk score stratification $[15,33]$. We think it would have been interesting to check SAL several times after CS in order to provide better understanding about their behavior. However, this is beyond the scope and the aims of the present research.

\section{Conclusions}

In summary, our study showed that the occurrence and the degree of hypoalbuminemia in the postoperative of CS is frequent and it may be associated with the development of several complications (especially septic or bleeding-related) and worst outcomes, even in long-term survival. Nutritional and inflammatory factors may be associated with the development of postoperative hypoalbuminemia. Postoperative SAL and factors associated with the development of mild to severe postoperative hypoalbuminemia may serve to early identify patients at risk of worst outcomes, which may ultimately help to intensity their monitoring and care in order to improve their status.

\section{Supplementary information}

Supplementary information accompanies this paper at https://doi.org/10. 1186/s13019-020-01133-y.

Additional file 1. Supplementary Figure 1 (consort diagram of the inclusion/ exclusion criteria), Supplementary Tables 1, 2 \& 3 (correspond to full model results of Tables 2,5 \& 6), Ethics approval, Study protocol and collected data.

\footnotetext{
Abbreviations

SAL: Serum albumin levels; CS: Cardiac Surgery; ICU: Intensive Care Unit CPB: Cardio-pulmonary by pass; ACC: Aortic cross clamping; SIRS: Systemic inflammatory response syndrome; EuroSCORE: European System for Cardiac Operative Risk Evaluation; APACHE: Acute Physiology and Chronic Health Evaluation; SAPS: Simplified Acute Physiology Score; AMI: Acute Myocardial Infarction; MAP: Mean arterial pressure; AKI: Acute kidney injury
}

\section{Acknowledgements}

We would like to thank CERCA program (Research Centers from Catalonia) from the Generalitat of Catalunya and IDIBELL (Bellvitge Biomedical Research Institute) for their support in the development of the present research.

\section{Authors' contributions}

DBF, JCLD, AP, were involved in the conception and design of the research, as well as performed statistical analysis and the writing of the manuscript. FE, $H T$, EF, DRC, MLC, were involved in the development of the database, the coordination and the acquisition of data, and the writing of the manuscript. GL was involved in the conception and design of the research and supervised the writing and statistical analysis of the manuscript. All authors read and approved the final version of this manuscript.

\section{Funding}

This research did not receive any specific grant from funding agencies in the public, commercial, or not-for-profit sectors.

\section{Availability of data and materials}

Data has been provided in detail throughout the manuscript. The datasets used and/or analyzed during the current study are available from the corresponding author on reasonable request.

Ethics approval and consent to participate

The study was approved by the Institutional Ethics Committee of our hospital (Comité d'Ëtica i Assajos Clínics de Hospital Universitari de Bellvitge; Barcelona, Spain); with approval number 39/07. Informed consent was waived due to the observational nature of our study (Details of the ethics approval and study protocol are provided as supplementary material).

Consent for publication

Not applicable.

\section{Competing interests}

Authors declare that no potential conflicts of interest exist.

\section{Author details}

${ }^{1}$ Intensive Care Department, Hospital Universitari de Bellvitge, C/Feixa Llarga s/n. 08907, L'Hospitalet de Llobregat, Barcelona, Spain. ${ }^{2}$ IDIBELL (Institut d'Investigació Biomèdica Bellvitge; Biomedical Investigation Institute of Bellvitge), Avda. Gran Via de L'Hospitalet 199, 08908, L'Hospitalet de Llobregat, Barcelona, Spain. ${ }^{3}$ Department of Anesthesiology, Pharmacology \& Intensive Care Medicine, Division of Anesthesiology, Geneva University Hospitals, Geneva, Switzerland. ${ }^{4}$ Department of Anesthesia and Intensive Care, IRCCS San Raffaele Scientific Institute, Milan, Italy. ${ }^{5}$ Vita-Salute San Raffaele University, Milan, Italy.

Received: 23 November 2019 Accepted: 4 May 2020 Published online: 11 May 2020

References

1. Fuhrman MP, Charney P, Mueller C. Hepatic proteins and nutrition assessment. J Am Diet Assoc. 2004;104:1258-64. https://doi.org/10.1016/j. jada.2004.05.213..

2. Weimann A, Braga M, Carli F, Higashiguchi T, Hübner M, Klek S, et al. ESPEN guideline: clinical nutrition in surgery. Clin Nutr. 2017;36:623-50. https://doi. org/10.1016/j.clnu.2017.02.013.

3. Montazerghaem $\mathrm{H}$, Safaie N, Nezhad V. Body mass index or serum albumin levels: which is further prognostic following cardiac surgery? J Cardiovasc Thorac Res. 2014;6:123-6. https://doi.org/10.5681/jcvtr.2014.026.

4. Engelman DT, Adams DH, Byrne JG, Aranki SF, Collins JJ Jr, Couper GS, Allred EN, Cohn LH, Rizzo RJ. Impact of body mass index and albumin on morbidity and mortality after cardiac surgery. J Thorac Cardiovasc Surg. 1999;118:866-73.

5. Karas PL, Goh SL, Dhital K. Is low serum albumin associated with postoperative complications in patients undergoing cardiac surgery? Interact Cardiovasc Thorac Surg. 2015;21:777-86. https://doi.org/10.1093/ icvts/ivv247

6. Critsinelis AC, Kurihara C, Kawabori M, Sugiura T, Lee W, Civitello AB, Morgan JA. Predictive value of preoperative serum albumin levels on 
outcomes in patients undergoing LVAD implantation. J Card Surg 2018; 33: 469-478. doi https://doi.org/10.1111/jocs.13745.

7. Koifman E, Magalhaes MA, Ben-Dor I, Kiramijyan S, Escarcega RO, Fang C, et al. Impact of pre-procedural serum albumin levels on outcome of patients undergoing transcatheter aortic valve replacement. Am J Cardiol. 2015;115:1260-4. https://doi.org/10.1016/j.amjcard.2015.02.009.

8. Bhamidipati CM, LaPar DJ, Mehta GS, Kern JA, Upchurch GR, Kron IL, Ailawadi G. Albumin is a better predictor of outcomes than body mass index following coronary artery bypass grafting. Surgery. 2011;150:626-34. https://doi.org/10.1016/.jsurg.2011.07.056.

9. de la Cruz KI, Bakaeen FG, Wang XL, Huh J, LeMaire SA, Coselli JS, Chu D. Hypoalbuminaemia and long-term survival after coronary artery bypass: a propensity score analysis. Ann Thorac Surg. 2011;91:671-6. https://doi.org/ 10.1016/j.athoracsur.2010.09.004.

10. Rady MY, Ryan T, Starr NJ. Peri-operative determinants of morbidity and mortality in elderly patients undergoing cardiac surgery. Crit Care Med. 1998;26:225-35. https://doi.org/10.1097/00003246-199802000-00016.

11. Rapp-Kesek D, Stahle E, Karlsson TT. Body mass index and albumin in the pre-operative evaluation of cardiac surgery patients. Clin Nutr. 2004;23: 1398-404. https://doi.org/10.1016/j.clnu.2004.06.006.

12. Lee EH, Chin JH, Choi DK, Hwang BY, Choo SJ, Song JG, Kim TY, Choi IC. Postoperative hypoalbuminemia is associated with outcome in patients undergoing off-pump coronary artery bypass graft surgery. J Cardiothorac Vasc Anesth. 2011;25:462-8. https://doi.org/10.1053/j.jvca.2010.09.008.

13. Corral-Velez V, Lopez-Delgado JC, Betancur-Zambrano NL, Lopez-Suñe N, Rojas-Lora M, Torrado H, Ballus J. The inflammatory response in cardiac surgery: an overview of the pathophysiology and clinical implications. Inflamm Allergy Drug Targets. 2015;13:367-70. https://doi.org/10.2174/ 1871528114666150529120801.

14. Furukawa $\mathrm{H}$, Tanemoto K. Frailty in cardiothoracic surgery: systematic review of the literature. Gen Thorac Cardiovasc Surg. 2015;63:425-33. https://doi. org/10.1007/s11748-015-0553-8

15. Coulson TG, Mullany DV, Reid CM, Bailey M, Pilcher D. Measuring the quality of perioperative care in cardiac surgery. Eur Heart I Qual Care Clin Outcomes. 2017;3:11-9. https://doi.org/10.1093/ehjqcco/qcw027.

16. Kramer AA, Zimmerman JE. Predicting outcomes for cardiac surgery patients after intensive care unit admission. Semin Cardiothorac Vasc Anesth. 2008:12:175-83. https://doi.org/10.1177/1089253208323413.

17. Eagle KA, Guyton RA, Davidoff R, Edwards FH, Ewy GA, Gardner TJ, et al. American College of Cardiology American Heart Association. ACC/AHA 2004 guideline update for coronary artery bypass graft surgery: a report of the American College of Cardiology/American Heart Association Task Force on Practice Guidelines (Committee to Update the 1999 Guidelines for coronary artery bypass graft surgery). Circulation 2004, 110: e340-e437. https://doi. org/10.1161/circ.110.14.e340.

18. Silva JM Jr, de Oliveira AM, Nogueira FA, Vianna PM, Pereira Filho MC, Dias LF, Maia VP, Neucamp Cde S, Amendola CP, Carmona MJ, Malbouisson LM. The effect of excess fluid balance on the mortality rate of surgical patients: a multicenter prospective study. Crit Care. 2013;17:R288. https://doi.org/10. 1186/cc13151.

19. Vincent IL, Pelosi P, Pearse R, Payen D, Perel A, Hoeft A, Romagnoli S, Ranieri VM, Ichai C, Forget P, Della Rocca G, Rhodes A. Perioperative cardiovascular monitoring of high-risk patients: a consensus of 12. Crit Care. 2015;19:224. https://doi.org/10.1186/s13054-015-0932-7.

20. Oliver E, Carrio ML, Rodríguez-Castro D, Javierre C, Farrero E, Torrado H, Castells E, Ventura JL. Relationships among haemoglobin level, packed red cell transfusion and clinical outcomes in patients after cardiac surgery. Intensive Care Med. 2009;35:1548-55. https://doi.org/10.1007/s00134-0091526-0.

21. Koertzen M, Punjabi P, Lockwood G. Pre-operative serum albumin concentration as a predictor of mortality and morbidity following cardiac surgery. Perfusion. 2013;28:390-4. https://doi.org/10.1177/ 0267659113488990.

22. Rich MW, Keller AJ, Schechtman KB, Marshall WG Jr, Kouchoukos NT. Increased complications and prolonged hospital stay in elderly cardiac surgical patients with low serum albumin. Am J Cardiol. 1989;63:714-8. https://doi.org/10.1016/0002-9149(89)90257-9.

23. Caso G, Vosswinkel JA, Garlick PJ, Barry MK, Bilfinger TV, McNurlan MA. Altered protein metabolism following coronary artery bypass graft (CABG) surgery. Clin Sci (Lond). 2008;114:339-46. https://doi.org/10.1042/ CS20070278.
24. Fleck A, Raines G, Hawker F, Trotter J, Wallace PI, Ledingham IM, Calman KC. Increased vascular permeability: a major cause of hypoalbuminaemia in disease and injury. Lancet. 1985;1:781-4. https://doi.org/10.1016/s01406736(85)91447-3.

25. Hotamisligil GS. Inflammation and metabolic disorders. Nature. 2006;444: 860-7. https://doi.org/10.1038/nature05485.

26. Hübner M, Mantziari S, Demartines N, Pralong F, Coti-bertrand P, Schäfer M. Postoperative albumin drop is a marker for surgical stress and a predictor for clinical outcome: a pilot study. Gastroenterol Res Pract. 2016;2016: 8743187. https://doi.org/10.1155/2016/8743187.

27. Agra Bermejo RM, González Ferreiro R, Varela Román A, Gómez Otero I, Kreidieh O, Conde Sabarís P, et al. Nutritional status is related to heart failure severity and hospital readmissions in acute heart failure. Int I Cardiol. 2017;230:108-14. https://doi.org/10.1016/j.jijcard.2016.12.067.

28. Ikizler TA. Nutrition, inflammation and chronic kidney disease. Curr Opin Nephrol Hypertens. 2008;17:162-7. https://doi.org/10.1097/MNH. Ob013e3282f5dbce.

29. Warren OJ, Smith AJ, Alexiou C, Rogers PL, Jawad N, Vincent C, Darzi AW, Athanasiou T. The inflammatory response to cardiopulmonary bypass: part Imechanisms of pathogenesis. J Cardiothorac Vasc Anesth. 2009;23:223-31. https://doi.org/10.1053/j.jvca.2008.08.007.

30. Pecoits-Filho R, Lindholm B, Stenvinkel P. The malnutrition, inflammation, and atherosclerosis (MIA) syndrome -- the heart of the matter. Nephrol Dial Transplant. 2002;17(Suppl 11):28-31. https://doi.org/10.1093/ndt/17.suppl_ 11.28.

31. Caironi P, Tognoni G, Masson S, Fumagalli R, Pesenti A, Romero M, et al. Albumin replacement in patients with severe Sepsis or septic shock. N Engl J Med. 2014;370:1412-21. https://doi.org/10.1056/NEJMoa1305727.

32. Lee EH, Kim WJ, Kim JY, Chin JH, Choi DK, Sim JY, Choo SJ, Chung CH, Lee JW, Choi IC. Effect of exogenous albumin on the incidence of postoperative acute kidney injury in patients undergoing off-pump coronary artery bypass surgery with a preoperative albumin level of less than $4.0 \mathrm{~g} / \mathrm{dl}$. Anesthesiology. 2016;124:1001-11. https://doi.org/10.1097/ALN. 0000000000001051 .

33. Rahmanian PB, Adams DH, Castillo JG, Carpentier A, Filsoufi F. Predicting hospital mortality and analysis of long-term survival after major noncardiac complications in cardiac surgery patients. Ann Thorac Surg. 2010;90:1221-9. https://doi.org/10.1016/j.athoracsur.2010.05.015.

\section{Publisher's Note}

Springer Nature remains neutral with regard to jurisdictional claims in published maps and institutional affiliations.
Ready to submit your research? Choose BMC and benefit from:
- fast, convenient online submission
- thorough peer review by experienced researchers in your field
- rapid publication on acceptance
- support for research data, including large and complex data types
- gold Open Access which fosters wider collaboration and increased citations
- maximum visibility for your research: over $100 \mathrm{M}$ website views per year
At BMC, research is always in progress. 